\title{
Cs-sorption in weathered biotite from Fukushima granitic soil
}

\author{
Ryosuke KIKuchi, Hiroki MuKaI, Chisaki Kuramata and Toshihiro Kogure \\ Department of Earth and Planetary Science, Graduate School of Science, The University of Tokyo, \\ 7-3-1 Hongo, Bunkyo-ku, Tokyo 113-0033, Japan
}

\begin{abstract}
The sorption characteristics of cesium (Cs) ions into weathered biotite with biotite-vermiculite interstratification collected from weathered granodiorite in Fukushima Prefecture, Japan has been investigated. Both single crystals and crushed powder forms of the weathered biotite were experimentally reacted with 20-2000 ppm $\mathrm{CsCl}$ aqueous solutions, and analyzed by powder X-ray diffraction (XRD), scanning electron microscopy (SEM) and scanning transmission electron microscopy (STEM) to examine the distribution of Cs inside the crystals. From the XRD pattern, the proportion of vermiculite unit layers in the weathered biotite was estimated at $\sim 12 \%$, with a tendency for segregation, and the whole XRD pattern was explained by the coexistence of biotite and vermiculite packets as well as the interstratified regions. Powder XRD of Cs-sorbed specimens showed that the $14.9 \AA$ peak of the vermiculite packets was weakened at a low Cs concentration in the solution. Single crystals of the weathered biotite with a polished edge-surface were immersed in the $\mathrm{CsCl}$ solutions and examined using SEM and high-angular annular dark field (HAADF) imaging in STEM. Cs was not only incorporated in the vicinity of the exposed surface but also penetrated deeply inside the crystals. These analyses and observations revealed the Cs-sorption process in weathered biotite. At first, Cs preferentially replaced specific vermiculite interlayers in the vermiculite packets. With a higher Cs concentration in the solution, the Cs-substituted vermiculite interlayers increased in the vermiculite packets, and vermiculite layers interstratified in biotite also incorporated Cs.
\end{abstract}

Keywords: Biotite, Vermiculite, Cesium, Sorption, XRD, HAADF-STEM

\section{INTRODUCTION}

Since the accident at Fukushima Daiichi Nuclear Power Plant (FDNPP) in March 2011, radioactive contamination in the soil around the plant has become a serious environmental problem in Japan. The major radioactive isotope is ${ }^{137} \mathrm{Cs}$, which has a longer half-life of $\sim 30$ years than other anthropogenic radioactive isotopes such as ${ }^{131} \mathrm{I}(\sim 8$ days) and ${ }^{134} \mathrm{Cs}$ ( $\sim 2$ years). Numerous previous studies have proposed that clay minerals, especially weathered micaceous minerals constitute favorable sorption and fixation sites for Cs (e.g., Wahlberg and Fishman, 1962; Sawhney, 1972; Francis and Brinkley, 1976; Komarneni and Roy, 1988; Cornell, 1993; McKinley et al., 2001). Because the contaminated areas in Fukushima are mainly covered with weathered granite soil (called 'masa' in Japanese), weathered biotite is abundant. Recently Mukai et al. (2014) reported that such weathered biotite crystals

doi:10.2465/jmps. 141218

R. Kikuchi, rkikuchi@eps.s.u-tokyo.ac.jp Corresponding author were frequently found in the contaminated soil in Fukushima as radioactive particles containing ${ }^{137} \mathrm{Cs}$. Hence, a basic understanding of $\mathrm{Cs}^{-}$-sorption process in weathered biotite should be important to understand the future fate of radioactive cesium in Fukushima.

In previous investigations (e.g., Sawhney, 1970, 1972; Kim et al., 1996; Kim and Kirkpatrick, 1997; Poinssot et al., 1999; Bostick et al., 2002; Liu et al., 2003; McKinley et al., 2004), four types of potential Cs-sorption site in weathered micas were proposed: (i) 'planar sites' on the basal planes of phyllosilicate layers; (ii) edge sites of phyllosilicate layers; (iii) 'frayed-edge' sites (FES), which refers to the transition zones between dehydrated (collapsed) and hydrous (expanded) interlayers; and (iv) interlayer sites. Several studies have reported that FES plays an important role in Cs sorption and retention (Sawhney, 1972; Zachara et al., 2002; McKinley et al., 2004). On the other hand, recent studies (Kogure et al., 2012; Okumura et al., 2014) have indicated that Cs penetrates deeply inside the crystals, along the interlayer regions by ion-exchange. In these studies, a high-resolu- 
tion transmission electron microscope (HRTEM) or a high-angle annular dark field scanning transmission electron microscope (HAADF-STEM) was used to visualize Cs-replaced interlayer regions.

In this study, we performed Cs-sorption experiments using single-crystalline or powdered forms of weathered biotites with biotite-vermiculite interstratification that were collected from Fukushima Prefecture, Japan. Although the concentration of radioactive $\mathrm{Cs}$ in the weathered biotite in the actual contaminated area is much lower (on the order of $\sim 0.1 \mathrm{ppm}$ at most) than in our experiments, a series of microanalytical methods, such as X-ray diffraction (XRD), scanning electron microscope (SEM) and HAADF-STEM were available to detect and visualize the existence of $\mathrm{Cs}$ incorporated into biotite. These approaches can provide an understanding at the microscopic level of the relationship between the weathering state of biotite and Cs sorption.

\section{MATERIALS AND METHODS}

\section{Materials}

The weathered biotite sample was collected from weathered granodiorite of the older type of Abukuma granitic rocks at Ono City in Tamura District, in the eastern part of Fukushima Prefecture, Japan (Endo and Kimiya, 1987; Kamei et al., 2003). This area is located about $40 \mathrm{~km}$ south-west of the FDNPP. The fresh granodiorite rock is composed of plagioclase, quartz, $\mathrm{K}$-feldspar, biotite, hornblende and accessory minerals such as apatite, zircon and ilmenite. The biotite crystals were collected from weathered granodiorite rock that was easily broken by hand into constituent minerals. The size of the biotite crystals is a few millimeters in width and thickness. Observation of petrographic thin sections showed that biotite crystals frequently contain inclusions of apatite, titanite, plagioclase and quartz.

\section{Cs-sorption experiments}

$\mathrm{CsCl}$ solutions with 20, 200, and $2000 \mathrm{ppm}$ of Cs (equivalent to $0.15,1.5$, and $15 \mathrm{mmol} \mathrm{L}^{-1}$ ) were prepared using $\mathrm{CsCl}$ agent with $99.9 \%$ purity (Wako Pure Chemical Industries, Ltd.) and purified water. The weathered biotite crystals collected were processed into two forms: powder crushed with an agate mortar and pestle, and cross sections of single crystals embedded in epoxy resin. The former was used for XRD analyses and the latter for electron microscopy. The surface of the cross sections of biotite was finished by ion-etching, as described by Inoue and Kogure (2012). Sorbent powder (150 mg) was im- mersed in $15 \mathrm{~mL}$ of the $\mathrm{CsCl}$ solutions for certain periods at $25.0 \pm 0.2{ }^{\circ} \mathrm{C}$. Then, the powder was separated through filter paper (11 $\mu \mathrm{m}$ particle retention). The biotite single crystals with their cross-sectional surface were immersed in $30 \mathrm{~mL}$ of the $\mathrm{CsCl}$ solutions for certain periods.

\section{Analyses of the original and Cs-sorbed specimens}

To observe the difference of the basal spacing before and after the Cs-sorption in the powder specimens, XRD analysis was conducted using a Rint-Ultima ${ }^{+}$diffractmeter (Rigaku) with $\mathrm{CuK \alpha}$ radiation emitted at $40 \mathrm{kV}$ and 30 $\mathrm{mA}$, a Ni filter, a $1 / 6^{\circ}$ divergence slit, an $8 \mathrm{~mm}$ anti-scatter slit, a $10 \mathrm{~mm}$ mask that confined the beam width, and a silicon strip X-ray detector (Rigaku D/teX Ultra2). The continuous scan rate were $10^{\circ}(2 \theta) / \mathrm{min}$ and data was collected at every $0.02^{\circ}(2 \theta)$.

The single crystals with the cross-sectional surface that reacted with the solutions were investigated initially using an S-4500 SEM (Hitachi) with an energy dispersive X-ray spectrometer (EDS) (Kevex Sigma). Backscatter electron (BSE) images were taken at $15 \mathrm{kV}$ with a YAG (Yttrium Aluminum Garnet)-type BSE detector (Hitachi) equipped to the SEM. Some specimens were processed into thin foils using an FB-2100 focused ion beam (FIB) with a microsampling system (Hitachi) and examined using JEM-2800 HAADF-STEM (JEOL). The STEM was operated with a Schottky-type field emission electron gun operated at an acceleration voltage of 200 $\mathrm{kV}$ and the $2 \theta$ angle of the annular detector for the HAADF-STEM images was from 55 to $248 \mathrm{mrad}$. The HAADF-STEM images were processed to remove noisy contrast from the damaged surface layers formed by the FIB process (Kogure and Okunishi, 2010).

\section{RESULTS AND DISCUSSION}

\section{Chemical compositions and XRD patterns of the orig- inal samples}

The chemical compositions (the average of analysis of 10 grains) of the weathered biotite and that of the fresh biotite in the granodiorite rock in this area were determined using SEM-EDS. They are as follows:

fresh biotite: $\left(\mathrm{K}_{0.92} \mathrm{Ca}_{0.04}\right)\left(\mathrm{Fe}_{1.37} \mathrm{Mg}_{0.90} \mathrm{Al}_{0.25} \mathrm{Ti}_{0.18}\right)\left(\mathrm{Al}_{1.11}\right.$ $\left.\mathrm{Si}_{2.89}\right) \mathrm{O}_{10}(\mathrm{OH})_{2}$

weathered biotite: $\left(\mathrm{K}_{0.75} \mathrm{Ca}_{0.07}\right)\left(\mathrm{Fe}_{1.46} \mathrm{Mg}_{0.89} \mathrm{Al}_{0.30} \mathrm{Ti}_{0.19}\right)$ $\left(\mathrm{Al}_{1.04} \mathrm{Si}_{2.96}\right) \mathrm{O}_{10}(\mathrm{OH})_{2}$

Because of apparent chemical inhomogeneity in the weathered biotite, X-ray spectra were obtained from a square of a few tens of micrometers on the polished cross section of the crystals without inclusions of other miner- 
als or large cleavages, in which the electron beam was scanned during $\mathrm{X}$-ray acquisition. In this calculation, iron was assumed to be ferrous. The composition of the fresh biotite is characterized as being rather rich in iron and octahedral aluminum, or an eastonite-siderophyllite component. Compared with the fresh biotite, the weathered biotite showed a decrease of potassium and an increase of calcium incorporation. With respect to octahedral cations, the weathered biotite contains more aluminum. This may be due to the existence of kaolinite in microcleavages.

XRD patterns from fresh and weathered biotites are presented in Figure 1. The pattern of weathered biotite shows two intense peaks, which correspond to 14.9 and $10.1 \AA$. The latter is attributed to the basal spacing of biotite. The former is regarded as the basal spacing of vermiculite and considering the $d$-value of $14.9 \AA$, the hydrated interlayer cations are expected to be calcium rather than magnesium. Actually, a considerable amount of calcium was detected in the weathered biotite by the SEM-EDS analysis.

To estimate the proportion of biotite and vermiculite layers in the crystal and the characteristics of their mixing, a simple simulation of one-dimensional XRD for the mixed-layer minerals was conducted using SYBILLAC, a program developed by Aplin et al. (2006) according to the procedure reported by Drits and Sakharov (1976). This program enables the comparison between the exper-

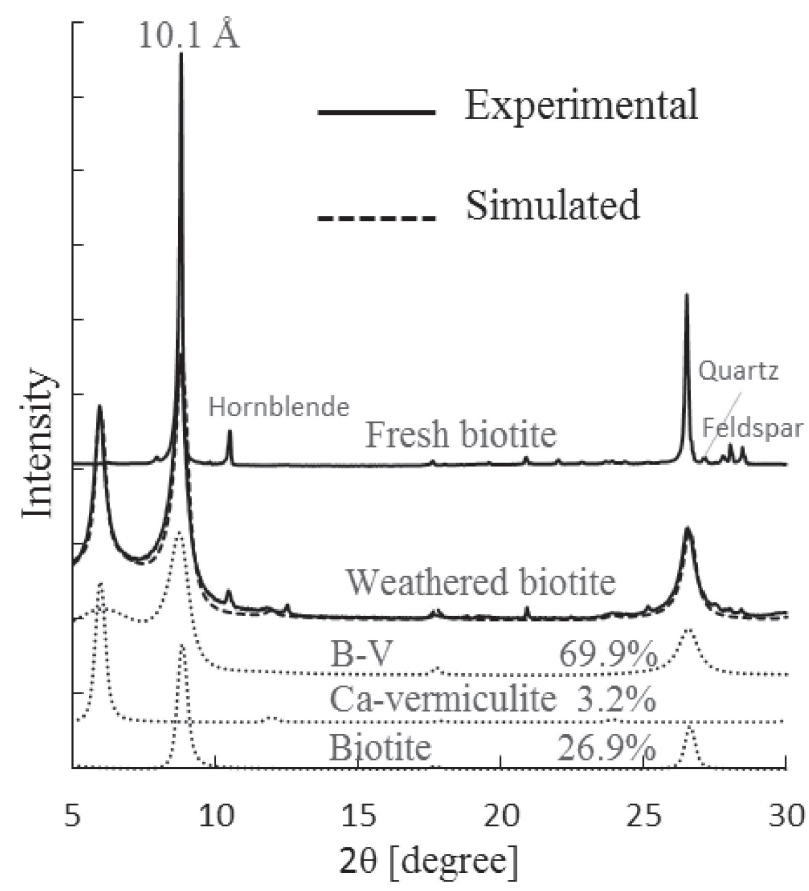

Figure 1. XRD patterns (solid lines) of fresh and weathered biotite used in this study, and a simulated XRD pattern (broken line) for the weathered biotite with three components (dotted lines) that compose the simulated pattern. imental and calculated XRD patterns with proposed models (e.g., Drits et al., 1997; Sakharov et al., 1999; Hubert et al., 2009). In the simulation, the compositions of biotite $\left(d_{001}=10.05 \AA\right)$ and $\mathrm{Ca}$-vermiculite $\left(d_{001}=14.9 \AA\right)$ layers were assumed to be $\mathrm{K}_{0.9}\left(\mathrm{Fe}_{1.5} \mathrm{Mg}_{1.0} \mathrm{Al}_{0.3} \mathrm{Ti}_{0.2}\right) \mathrm{Si}_{4}$ $\mathrm{O}_{10}(\mathrm{OH})_{2}$ and $\left(\mathrm{Ca} \cdot 7 \mathrm{H}_{2} \mathrm{O}\right)_{0.3}\left(\mathrm{Fe}_{1.5} \mathrm{Mg}_{1.0} \mathrm{Al}_{0.3} \mathrm{Ti}_{0.2}\right) \mathrm{Si}_{4} \mathrm{O}_{10}$ $(\mathrm{OH})_{2}$, respectively. For the $\mathrm{Z}$-coordinates of the atomic sites in the biotite and $\mathrm{Ca}$-vermiculite layers, the atomic parameters from X-ray structure analyses by Brigatti et al. (1991) and Slade et al. (1985) were used, respectively. The valuables to reproduce the experimental pattern were the proportion of the vermiculite layer $\left(W_{\mathrm{v}} ; 0 \leq W_{\mathrm{v}} \leq 1\right)$ and the probability that the vermiculite layer was succeeded by the same vermiculite layer $\left(P_{\mathrm{vv}}\right)$. If $P_{\mathrm{vv}}=1$, the two layers are completely segregated. In contrast, if $P_{\mathrm{vv}}=0$, the two layers are mixed maximally. If $P_{\mathrm{vv}}=W_{\mathrm{v}} /$ $\left(1-W_{\mathrm{v}}\right)$, the stacking is completely random.

The best-fit calculated pattern is presented in Figure 1 by a broken line, as well as the experimental one with by a solid line. As shown in this figure, the calculated pattern was the summation of three components: biotite, $\mathrm{Ca}$-vermiculite and $\mathrm{B}-\mathrm{V}$. The first two components are just pure phases, and the last one is the interstratified phase with $W_{\mathrm{v}}=0.13, P_{\mathrm{vv}}=0.26$, showing that this component is mainly composed of the biotite layers and the vermiculite layers are slightly segregated, because $P_{\mathrm{vv}}$ is larger than $W_{\mathrm{v}} /\left(1-W_{\mathrm{v}}\right)=0.15$. The proportions of the three components are $30.9,3.2$, and $65.9 \%$. The total proportion of the vermiculite layers in the three components is $12.3 \%$. This result is semi-quantitatively in agreement with the decrease of $\mathrm{K}$ in the weathered biotite compared with that in the fresh one in terms of their chemical compositions, determined by SEM-EDS analysis as stated above.

\section{Characterization of Cs-sorbed samples}

XRD of powder specimens. Figure 2 shows XRD patterns of powder specimens immersed in the $\mathrm{CsCl}$ solution at the various concentrations for 24 hours (Fig. 2a) and with the $200 \mathrm{ppm}$ solution for various durations (Fig. 2b). It is notable that the $14.9 \AA$ peak decreased in intensity and disappeared as the concentration increased in Figure $2 \mathrm{a}$, and this peak abruptly disappeared within 20 minutes of immersion in Figure $2 b$. These results suggest that $\mathrm{Cs}$ ions selectively replaced hydrated $\mathrm{Ca}$ ions in the vermiculite or vermiculite-dominant packets within a few tens of minutes and the interlayer collapsed due to the dehydration (Kogure et al., 2012; Tamura et al., 2014). The full width at half-maximum (FWHM) of the $10.1 \AA$ peak tends to decreased gradually with the increase of Cs concentration in the solution, except for the $20 \mathrm{ppm}$. One the 

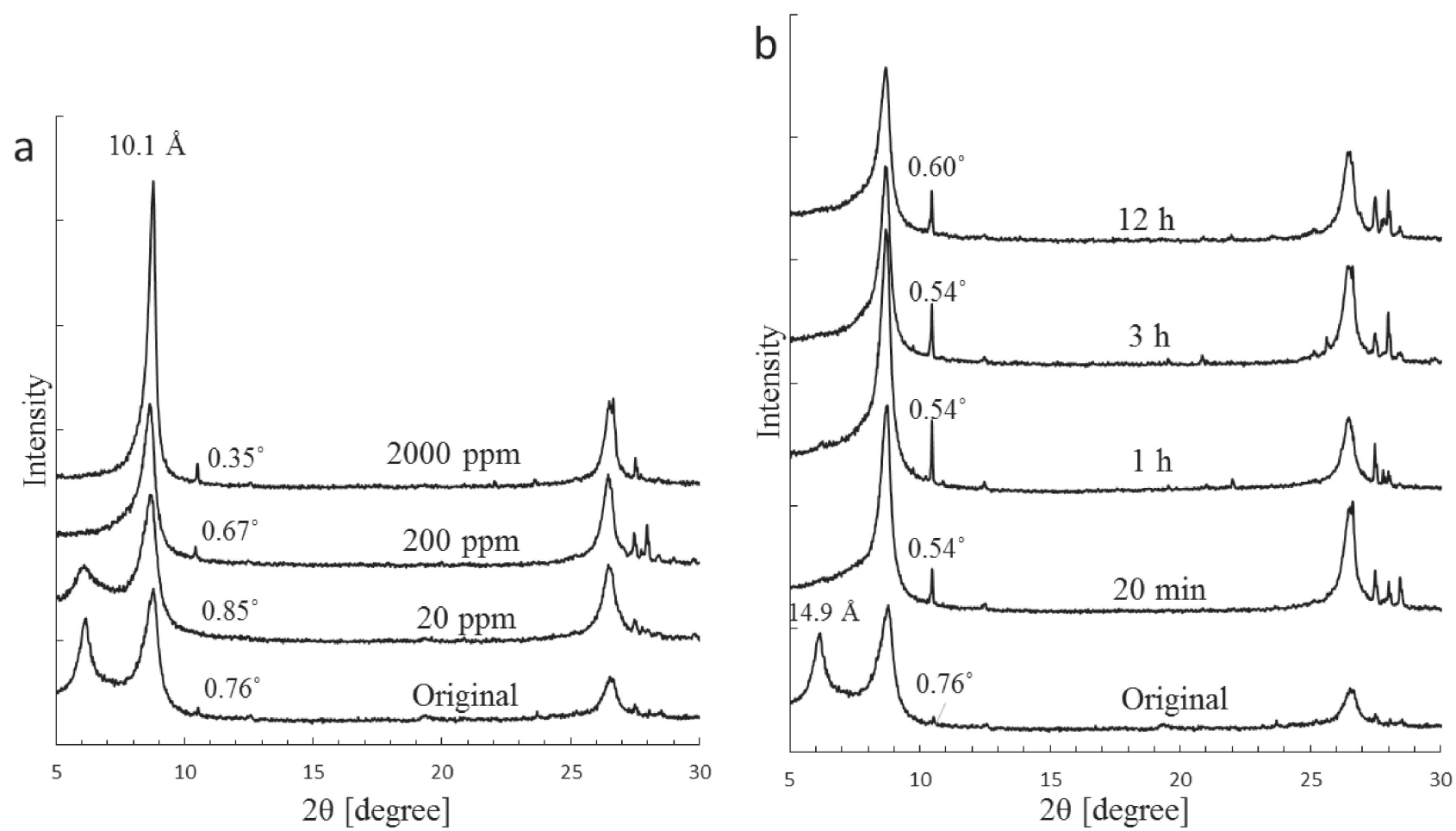

Figure 2. Experimental XRD patterns of the specimens after reacting with $\mathrm{CsCl}$ solutions of (a) various concentrations for 24 hours, and (b) $200 \mathrm{ppm}$ for various duration times. The value attached to each pattern is the FWHM of the $10.1 \AA$ peak, determined as described in Suzuki et al. (2012).

other hand, the FWHM decreased within 20 minutes at first and did not change with a longer duration. The FWHM is influenced mainly by the fine interstratification of the $14.9 \AA$ vermiculite layers in the biotite packets, or B-V interstratification. Although the values of FWHM slightly vary due to the inhomogeneity of interstratification, the tendency of the gradual decrease of FWHM according to the increase of the concentration suggests that the incorporation of $\mathrm{Cs}$ in the interstratified vermiculite layers (e.g., monolayer) in the biotite packets is less preferable than in the vermiculite packets. Owing to the large radius of $\mathrm{Cs}$, the Cs-substituted vermiculite layer has the basal spacing of ca $10.6 \AA$ (Kogure et al., 2012). However, unlike in previous works (e.g, Kogure et al., 2012; Tamura et al., 2014), the influence of such larger basal spacing on the XRD pattern, for instance shift of the biotite peak, was not observed in Figure 2. This is probably due to the smaller proportion of the vermiculite layers in the present biotite than in Transvaal vermiculite used in these previous experiments. The exceptional broadening of the FWHM at $20 \mathrm{ppm}$ in Figure 2a was probably resulted from the peak shift from 14.9 to $10.6 \AA$.

Next, the XRD pattern after Cs sorption was also simulated using SYBILLA. In this simulation, the proportions of the three components, and $W_{\mathrm{v}}$ and $P_{\mathrm{vv}}$ for the B-V interstratification were fixed as in Figure 1 be- cause these parameters should not be altered by the Cs sorption. Only the crystal parameters for the $\mathrm{Ca}$-vermiculite layer were replaced by those for the Cs-vermiculite layer with Cs (occupancy is 0.6 and no water molecules) at the interlayer site, basal spacing of $10.6 \AA$ and interlayer separation of $4.5 \AA$. Figure 3 shows a comparison of the simulated XRD pattern and the experimental one for the specimen immersed in the $\mathrm{CsCl}$ solution of 2000 ppm for 24 hours. The correspondence between the two patterns is unsatisfactory; in particular, the left side of the $10.1 \AA$ peak in the experimental pattern cannot be reproduced. Hence, another simulation was conducted with the assumption that the vermiculite layers in the vermiculite packets were fully replaced by $\mathrm{Cs}^{-}$-vermiculite layers, but they were partially replaced in the B-V interstratified regions. Figure $3 \mathrm{~b}$ shows that $68 \%$ of the initial 'B-V' was unchanged and $32 \%$ was changed to ' $\mathrm{B}-\mathrm{V}$ ' with $\mathrm{Cs}$-vermiculite layers. Although the fitting is still not perfect, the profiles of the 10.1 and $3.35 \AA$ peaks were considerably improved, compared with Figure 3a. This result suggests that original vermiculite layers in the B-V interstratification were not completely Cs-substituted, even by immersion in the 2000 ppm solution for 24 hours.

SEM-EDS analysis of Cs-sorbed single crystals. Single crystal specimens were examined by SEM after the sorption experiments. Figure 4 shows back-scattered 

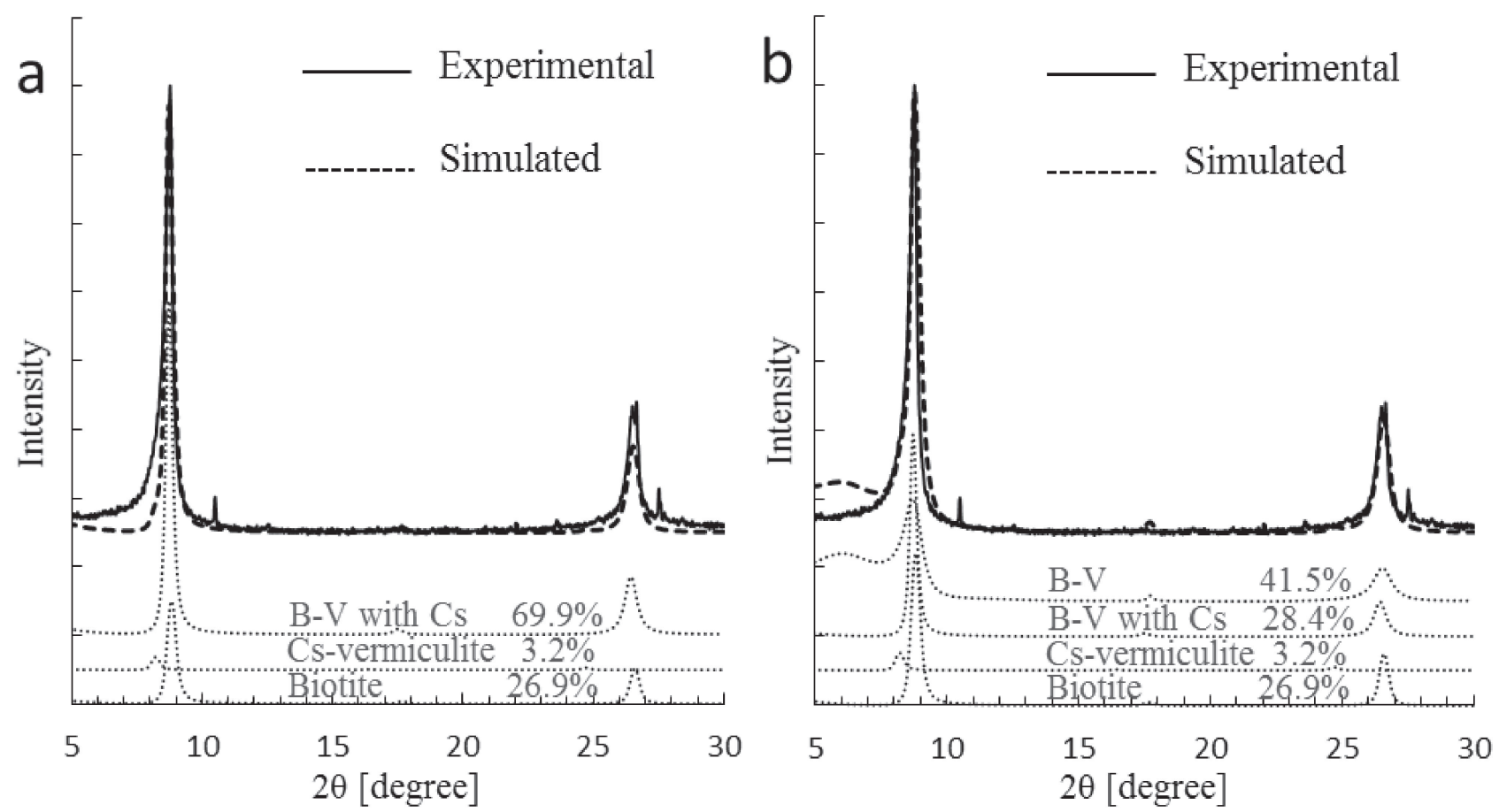

Figure 3. Experimental XRD pattern after reacting with the $2000 \mathrm{ppm}$ solution for 24 hours (solid line) and simulated XRD ones (broken line), (a) assuming that all of the vermiculite interlayers are replaced by Cs and (b) that about $60 \%$ of the vermiculite interlayers in the B-V interstratification are not replaced by Cs. The XRD patterns of the components constituting the simulated pattern are also presented as dotted lines below the simulated pattern.

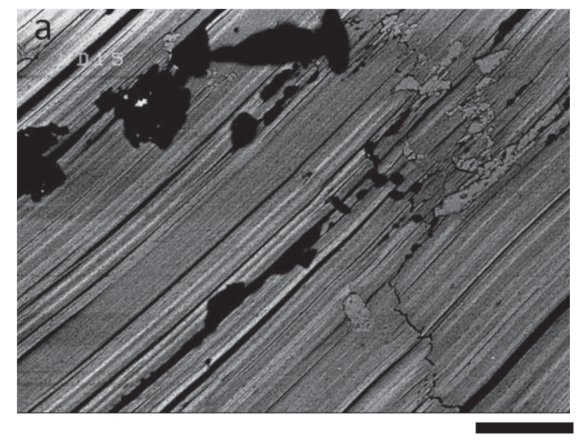

$100 \mu \mathrm{m}$

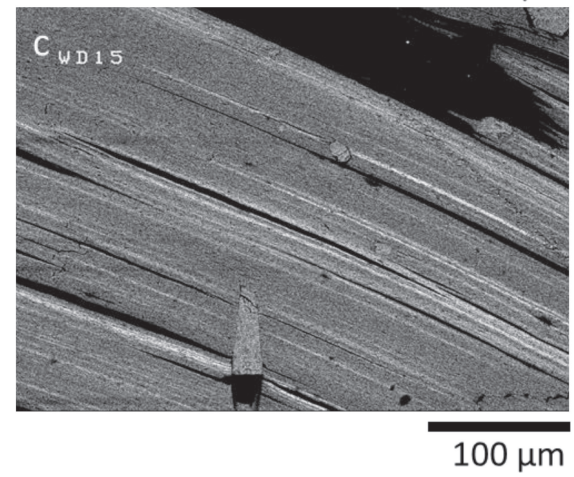

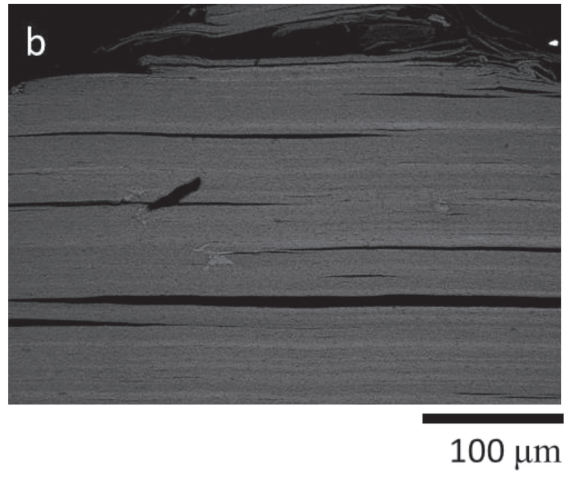

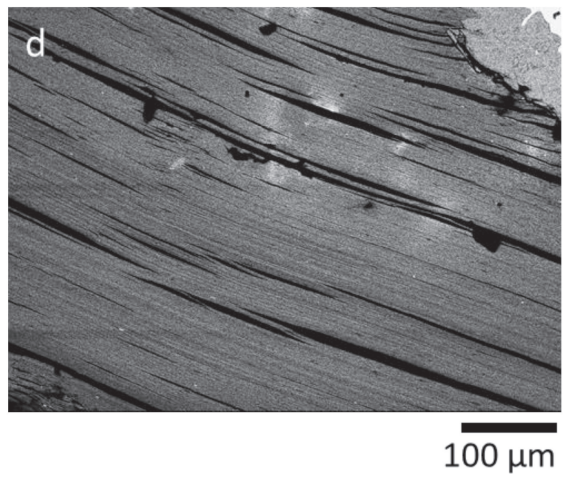

Figure 4. Back-scattered electron (BSE) images of the exposed surface of the single crystal specimens after reacting with the 2000 ppm solution for (a) 24 hours, and (b) 1 hour, (c) $200 \mathrm{ppm}$ for 24 hours and (d) 20 ppm for 24 hours. electron (BSE) images of the specimen reacted with the $\mathrm{CsCl}$ solution with various concentrations and durations. Banded bright contrasts were observed on the surface of the specimen. Such contrasts were weaker for lower concentrations or shorter durations. The EDS analysis showed enrichment of $\mathrm{Cs}$ and depletion of $\mathrm{K}$ at the bright 

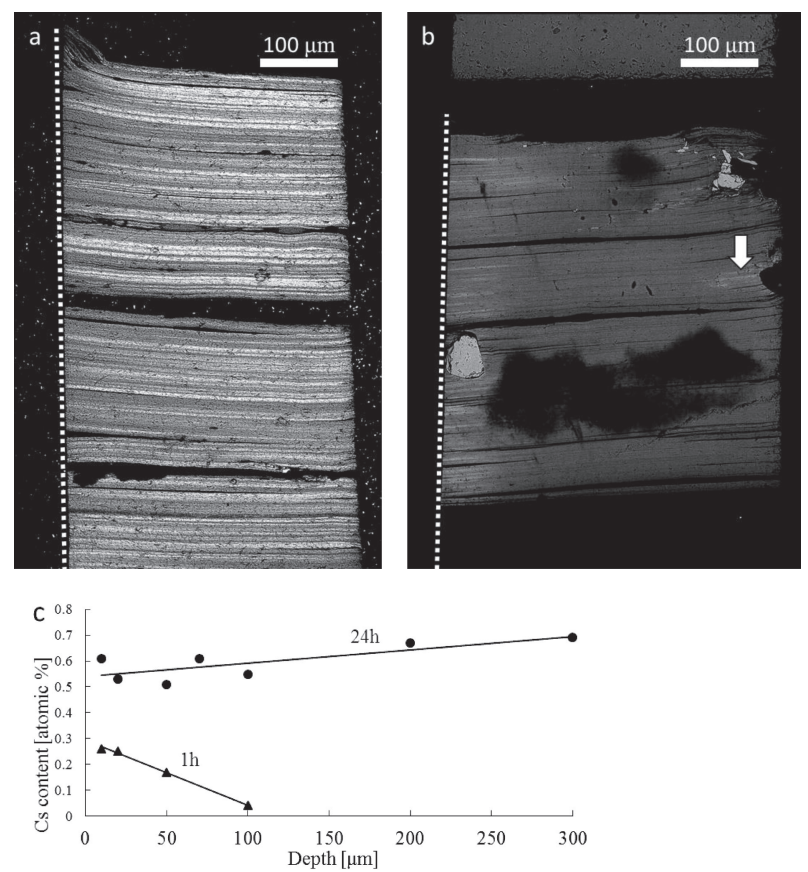

Figure 5. BSE images of single crystal specimens after reacting with the $2000 \mathrm{ppm} \mathrm{CsCl}$ solution for (a) 24 hours, and (b) 1 hour. The white dotted line indicates the exposed surface during the reaction and Cs was expected to incorporate from the surface to the right, inside the crystal. The edge of the right side was covered with resin. The bright contrast indicated by the white arrow is due to inclusions with high iron content. (c) The depth profile of Cs content was determined by SEM-EDS. X-ray spectra were obtained from a vertically elongated rectangular region (height: a few tens of micrometers, width: a few micrometers), considering the inhomogeneity.

contrast, indicating that such contrast results from Cs incorporation into the vermiculite-dominant packets.

Next, these cross-sectional specimens were sectioned again, perpendicular to the exposed surface. Figure 5 presents two BSE images, with the same recording conditions, such as in terms of brightness and contrast. As shown in Figure 5a (2000 ppm for 24 hours), the banded bright contrasts can be traced down to the opposite side of the crystal of $300 \mu \mathrm{m}$ in thickness. Furthermore, the EDS analysis indicated that sorbed Cs concentration is almost the same along the depth (Fig. 5c). On the other hand, the BSE image of the specimen after reacting with the $2000 \mathrm{ppm}$ solution for 1 hour showed that the contrasts by the Cs incorporation near the exposed surface were terminated at around $100 \mu \mathrm{m}$ in depth (Fig. 5b), indicating that the penetration of Cs into the interlayer sites proceeded down to this depth in one hour. Figure $6 \mathrm{a}$ is a magnified BSE image of Figure $5 \mathrm{~b}$ near the reacted surface. Some banded bright contrasts have become darker than the surroundings inside of the crystal. EDS X-ray spectra (Fig. 6b) indicated that such banded
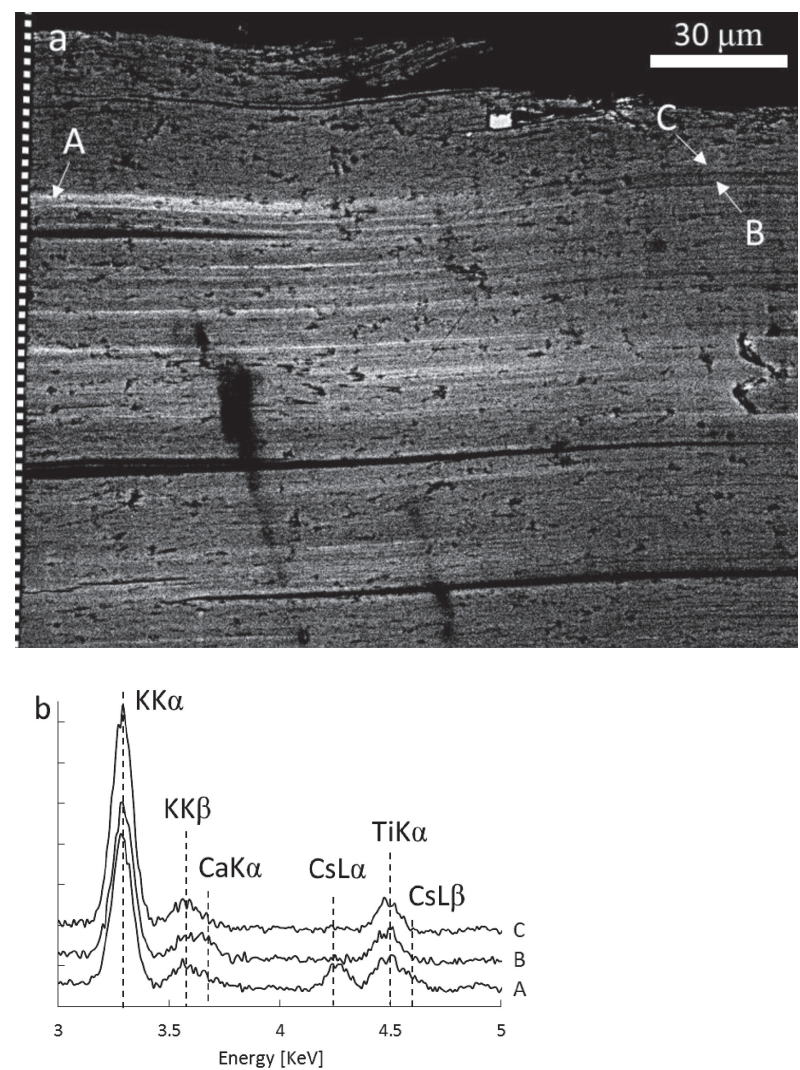

Figure 6. (a) Magnified BSE image of the portion of the specimen area in Figure 5b. The white dotted line indicates the exposed surface. The white arrows indicate the points analyzed by EDS. Some banded bright contrasts change to dark contrasts in the deeper side. (b) X-ray spectra obtained from three points in Figure $6 a$.

region ('A' and ' $\mathrm{B}$ ') is deficient in $\mathrm{K}$, and point $\mathrm{A}$ (bright region) contains $\mathrm{Cs}$ whereas point $\mathrm{B}$ (dark region) contains $\mathrm{Ca}$. Hence, it is suggested that such banded contrast regions were initially vermiculite-dominant packets with hydrated calcium-occupied interlayers, and Cs intensively replaced $\mathrm{Ca}$ during the reaction with the solutions.

HAADF-STEM observation. Finally, HAADFSTEM imaging was conducted to confirm the Cs-sorption features in the weathered biotite suggested by the XRD and SEM-EDS analyses, by observing biotite, vermiculite and Cs-substituted layers directly. Figure 7 shows a HAADF-STEM image in the vicinity of the exposed surface of a single-crystal specimen immersed in the $200 \mathrm{ppm}$ solution for 24 hours. The orientation of the crystal was set as the incident electron beam parallel to the $\mathrm{X}_{\mathrm{i}}(\mathrm{i}=1$ to 3 ) direction in phyllosilicates (Bailey, 1988). In Figures $7 \mathrm{~b}$ and $7 \mathrm{c}$, we can distinguish three kinds of contrasts at the interlayer regions $(\mathrm{Cs}, \mathrm{K}$ and $\mathrm{V}$ in Fig. 7c). The brightest contrast (Cs) is definitely that corresponding to the Cs-occupied interlayer, where each Cs column can be resolved with a separation of $4.5 \AA$ 

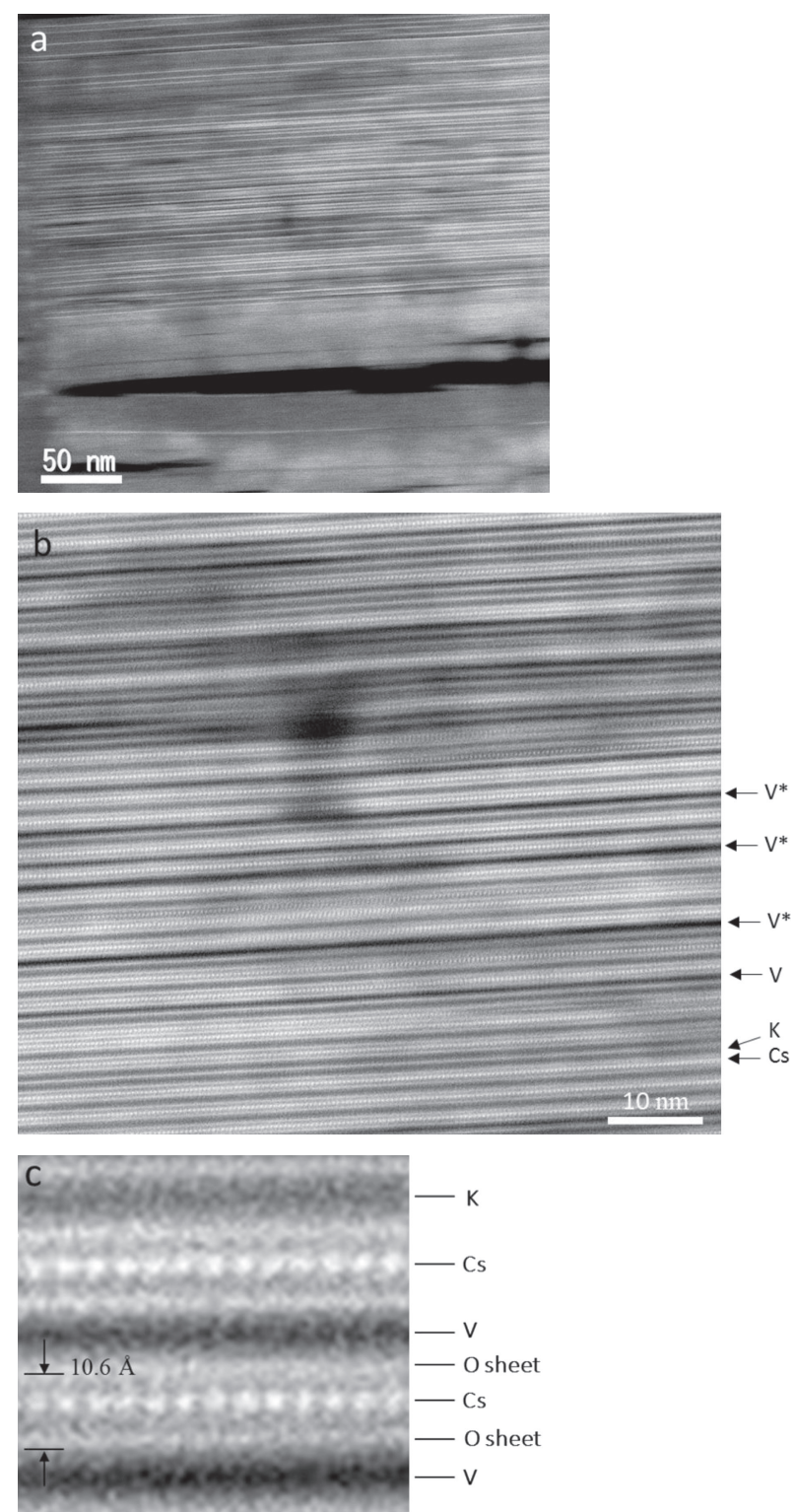

Figure 7. (a) Low-magnification HAADF images of specimens after reacting with the $\mathrm{CsCl} 200 \mathrm{ppm}$ solutions for 24 hours. The left side is the exposed surface and Cs penetrated towards the right. (b) Magnified and filtered (Kogure and Okunishi, 2010) image of the center of the image in (a). (c) More magnified image to show correspondence between atomic sheets in the crystal structure and image contrast. In (b), Cs-substituted, Koccupied and empty interlayers are denoted by $\mathrm{Cs}, \mathrm{K}$ and $\mathrm{V}$, respectively. The interlayers denoted by $\mathrm{V}^{*}$ are those with a wider interlayer spacing than those denoted by $\mathrm{V}$ (see the text).

(Okumura et al., 2014). The medium contrast (K) corresponds to the $\mathrm{K}$-occupied interlayer, or that in biotite, where spots corresponding to the $\mathrm{K}$-columns can be faintly identified. The darkest one (V) probably corresponds to the interlayer of vermiculite, which became empty and collapsed as a result of the removal of hydrated $\mathrm{Ca}$ ions due to the vacuum in STEM (Kogure and
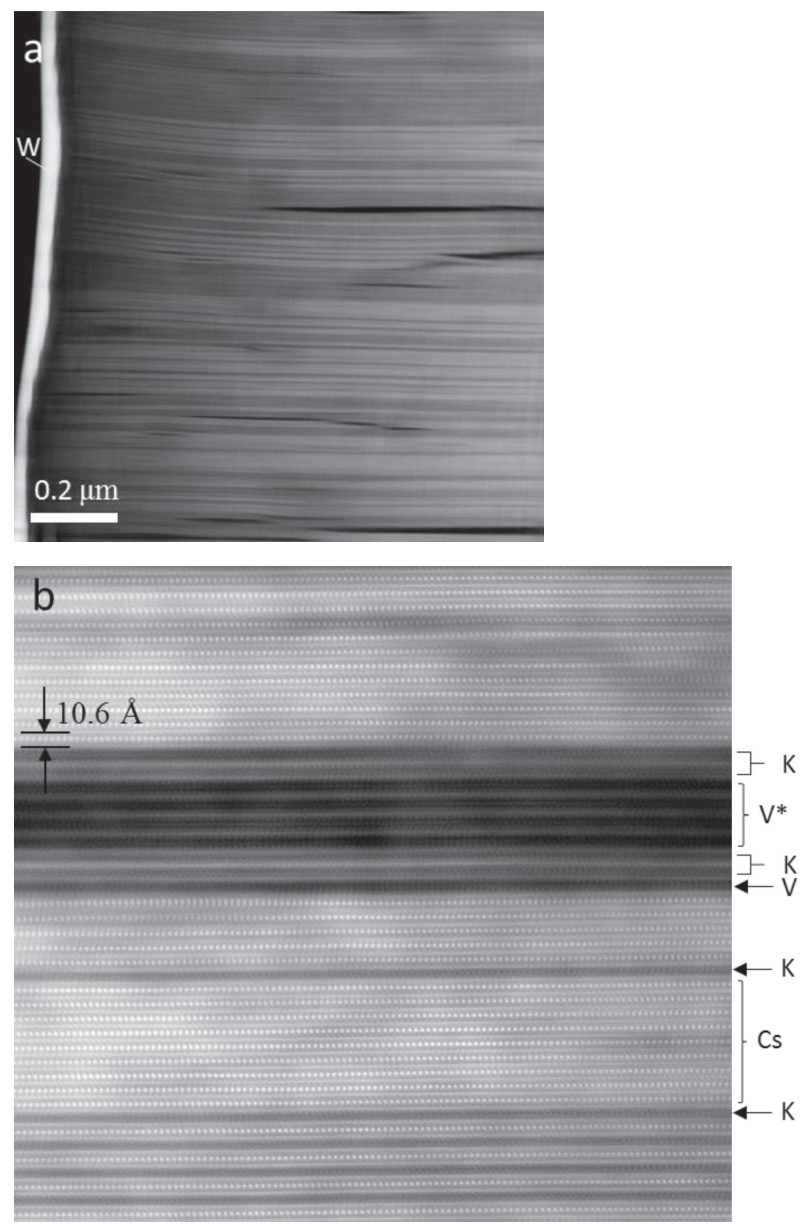

Figure 8. HAADF images of the specimen after reacting with the 2000 ppm solution for 24 hours. (a) Low magnified image. The left side is the exposed surface during the reaction and Cs penetrated towards the right. ' $\mathrm{W}$ ' indicates the tungsten protective coating formed in the FIB sample preparation. (b) Magnified and filtered image of the same specimen. The symbols (Cs, K, $\mathrm{V}$ and $\mathrm{V}^{*}$ ) are the same as those in Figure $7 \mathrm{~b}$.

Murakami, 1996). The area in Figure 7 is considered originally to have been the $\mathrm{B}-\mathrm{V}$ interstratified region and a number of vermiculite interlayers were substituted by Cs. However, several unsubstituted vermiculite layers are still present in the vicinity. This is similar to the result reported by Kogure et al. (2012) for Cs-substituted Transvaal vermiculite, and also supports the result of the XRD analysis (Fig. 3b). A hypothesis to explain this phenomenon is that chemical compositions of the vermiculite layers are not homogeneous in the specimen; some of them can easily and/or rapidly replace hydrated $\mathrm{Ca}$ by $\mathrm{Cs}$, whereas others need a longer time or a higher concentration of $\mathrm{Cs}$ in the solution. On the other hand, Figure 8 shows another HAADF image taken from the specimen immersed in $2000 \mathrm{ppm}$ solution for 24 hours. Regions with many Cs-substituted interlayers are ob- 
served without interstratification of $\mathrm{K}$ or empty interlayers, which were probably the result of Cs-substitution at the vermiculite packets, as suggested by the XRD analysis (Figs. 2 and 3).

In addition to the overview of the HAADF-STEM images is as stated above, detailed analysis of the images revealed several findings. As shown in Figure 7, the remaining vermiculite layers is not uniform. The layers with an asterisk $\left(\mathrm{V}^{*}\right)$ have a wider basal spacing of 12 $14 \AA$, whereas the others have that of $\sim 10 \AA$. Similar vermiculite layers with thicker basal spacing are also observed around the center in Figure 8b. They are probably not microcleavages because the spacing is rather uniform. If they are chlorite layers, the contrast for the hydroxide sheet should appear at the center of the interlayer space. Kogure et al. (2013) reported two types of smectite-like layer in corrensite, one of which collapsed to $\sim 10.2 \AA$ and the other collapsed to $12.4 \AA$ under a vacuum in TEM. They attributed this difference to the inhomogeneity of layer charge as proposed by Ferrage et al. (2005). Variation of the layer spacing of vermiculite layers in Figures 7 and 8 may indicate the fluctuation of their layer charge in the weathered biotite. Besides, it seems that the brightness of the Cs-substituted interlayers is not completely uniform, but varies considerably. The origin of this variation may be related to the occupancy of Cs at the interlayer sites, but differences in the imaging conditions cannot be ruled out.

\section{CONCLUDING REMARKS}

Cs-sorption experiments were conducted using weathered biotite collected from Fukushima granite, and the distribution of $\mathrm{Cs}$ in the crystals was investigated using XRD, SEM-EDS and HAADF-STEM. Cs was incorporated preferentially into vermiculite packets at a low Cs concentration in the solution. At a higher Cs concentration, the remaining vermiculite interlayers interstratified in biotite were substituted by Cs. These results provide valuable insight into the Cs-sorption features of weathered biotite, which is common in Fukushima, but the concentrations of $\mathrm{Cs}$ sorbed in the weathered biotite in these experiments are probably several orders higher than the actual contamination level in Fukushima. Accordingly, further experiments are necessary to confirm whether the results in this study can be extrapolated to such a low concentration level.

\section{ACKNOWLEDGMENTS}

The authors are grateful to Eiko Fujii, Sayako Inoue, Taiga Okumura and Akihito Kumamoto at the University of
Tokyo for assistance with the experiments and valuable advice. They also thank Kenji Tamura at the National Institute for Materials Sciences for preparation of the $\mathrm{CsCl}$ solutions. Part of this work was supported by Grants-in-Aid for science research (No. 2434133 and No. 2460369) by MEXT, Japan. A part of this work was conducted in Research Hub for Advanced Nano Characterization, The University of Tokyo, under the support of 'Nanotechnology Platform' (No. 12024046) from MEXT, Japan. This work was also supported by 2014 JAEA contract research for Fukushima environment recovery, 'Study on Cs adsorption and desorption process on clay minerals'.

\section{REFERENCES}

Aplin, A.C., Matenaar, I.F., McCarty, D.K. and van der Pluijm, B.A. (2006) Influence of mechanical compaction and clay mineral diagenesis on the microfabric and pore-scale properties of deep-water Gulf of Mexico mudstones. Clays and Clay Minerals, 54, 500-514.

Bailey, S.W. (1988) Polytypism of 1:1 layer silicates. In Hydrous Phyllosilicates (Exclusive of micas) (Bailey, S.W. Ed.). Reviews in Mineralogy, Vol. 19, Mineralogical Society of America, Washington, D.C., 9-27.

Bostick, B.C., Vairavamurthy, M.A., Karthikeyan, K.G. and Chorover, J. (2002) Cesium Adsorption on Clay Minerals: An EXAFS Spectroscopic Investigation. Environmental Science \& Technology, 36, 2670-2676.

Brigatti, M.F., Galli, E. and Poppi, L. (1991) Effect of Ti substitution in biotite-1M crystal chemistry. American Mineralogist, 76, 1174-1183.

Cornell, R.M. (1993) Adsorption of cesium on minerals: a review. Journal of Radioanalytical and Nuclear Chemistry, 171, 483500.

Drits, V.A. and Sakharov, B.A. (1976) X-ray structural analysis of mixed-layer minerals. pp. 256, Nawka, Moscow (in Russian).

Drits, V.A., Sakharov, B.A., Lindgreen, H. and Salyn, A. (1997) Sequential structure transformation of illite-smectite-vermiculite during diagenesis of Upper Jurassic shales, North Sea and Denmark. Clay Minerals, 32, 351-371.

Endo, N. and Kimiya, K. (1987) Distribution of Weathering Crust of Granitic Rocks and Alteration of Biotite in the Middle of Abukuma Mountains, Northeastern Japan. Journal of Japan Society of Engineering Geology, 28, 1-14 (in Japanese with English abstract).

Ferrage, E., Lanson, B., Sakharov, B.A. and Drits, V.A. (2005) Investigation of smectite hydration properties by modeling experimental X-ray diffraction patterns: Part I. Montmorillonite hydration properties. American Mineralogist, 90, 13581374 .

Francis, C.W. and Brinkley, F.S. (1976) Preferential adsorption of ${ }^{137} \mathrm{Cs}$ to micaceous minerals in contaminated freshwater sediment. Nature, 260, 511-513.

Hubert, F., Caner, L., Meunier, A. and Lanson, B. (2009) Advances in characterization of soil clay mineralogy using X-ray diffraction: from decomposition to profile fitting. European Journal of Soil Science, 60, 1093-1105.

Inoue, S. and Kogure, T. (2012) Electron backscatter diffraction 
(EBSD) analyses of phyllosilicates in petrographic thin sections. American Mineralogist, 97, 755-758.

Kamei, A., Takagi, T. and Kubo, K. (2003) Geology and Petrography of the Abukuma Granites in the Hiyama District, Fukushima Prefecture, NE Japan. Bulletin of the Geological Survey of Japan, 54, 395-409 (in Japanese with English abstract).

Kim, Y., Cygan, R.T. and Kirkpatrick, R.J. (1996) ${ }^{133}$ Cs NMR and XPS investigation of cesium adsorbed on clay minerals and related phases. Geochimica et Cosmochimica Acta, 60, 10411052.

Kim, Y. and Kirkpatrick, R.J. (1997) ${ }^{23} \mathrm{Na}$ and ${ }^{133} \mathrm{Cs}$ NMR study of cation adsorption on mineral surfaces: Local environments, dynamics, and effects of mixed cations. Geochimica et Cosmochimica Acta, 61, 5199-5208.

Kogure, T. and Murakami, T. (1996) Direct identification of biotite/ vermiculite layers in hydrobiotite using high-resolution TEM. Mineralogical Journal, 18, 131-137.

Kogure, T. and Okunishi, E. (2010) Cs-corrected HAADF-STEM imaging of silicate minerals. Journal of Electron Microscopy, $59,263-271$.

Kogure, T., Morimoto, K., Tamura, K., Sato, H. and Yamaguchi, A. (2012) XRD and HRTEM evidence for fixation of cesium ions in vermiculite clay. Chemistry Letters, 41, 380-382.

Kogure, T., Drits, V.A. and Inoue, S. (2013) Structure of mixedlayer corrensite-chlorite revealed by high-resolution transmission electron microscopy (HRTEM). American Mineralogist, 98, 1253-1260.

Komarneni, S. and Roy, R. (1988) A cesium-selective ion sieve made by topotactic leaching of phlogopite mica. Science, 239, 1286-1288.

Liu, C., Zachara, J.M., Smith, S.C., McKinley, J.P. and Ainworth, C.C. (2003) Desorption kinetics of radiocesium from subsurface sediments at Hanford site, USA. Geochimica et Cosmochimica Acta, 67, 2893-2912.

McKinley, J.P., Zeissler, C.J., Zachara, J.M., Serne, R.J., Lindstrom, R.M., Schaef, H.T. and Orr, R.D. (2001) Distribution and retention of ${ }^{137} \mathrm{Cs}$ in sediments at the Hanford Site, Washington. Environmental Science \& Technology, 35, 34333441.

McKinley, J.P., Zachara, J.M., Heald, S.M., Dohnalkova, A., Newville, M.G. and Sutton, S.R. (2004) Microscale distribution of cesium sorbed to biotite and muscovite. Environmental Sci- ence \& Technology, 38, 1017-1023.

Mukai, H., Hatta, T., Yamada, H., Yaita, T. and Kogure, T. (2014) Speciation of radioactive soil particles in the Fukushima contaminated area by IP autoradiography and microanalyses. Environmental Science \& Technology, 48, 13053-13059.

Okumura, T., Tamura, K., Fujii, E., Yamada, H. and Kogure, T. (2014) Direct observation of cesium at the interlayer region in phlogopite mica. Microscopy, 63, 65-72.

Poinssot, C., Baeyens, B. and Bradbury, M.H. (1999) Experimental and modeling studies of caesium sorption on illite. Geochimica et Cosmochimica Acta, 63, 3217-3227.

Sakharov, B.A., Lindgreen, H., Salyn, A.L. and Drits, V.A. (1999) Determination of illite-smectite structures using multispecimen XRD profile fitting. Clays and Clay Minerals, 47, 555566.

Sawhney, B.L. (1970) Potassium and cesium ion selectivity in relation to clay mineral structure. Clays and Clay Minerals, 18, 47-52.

Sawhney, B.L. (1972) Selective sorption and fixation of cations by minerals: a review. Clays and Clay Minerals, 20, 93-100.

Slade, P.G., Stone, P.A. and Radoslovich, E.W. (1985) Interlayer structures of the two layer hydrates of $\mathrm{Na}^{-}$and $\mathrm{Ca}-$-vermiculites. Clays and Clay Minerals, 33, 51-61.

Suzuki, M., Kim, H., Mukai, H., Nagasawa, H. and Kogure, T. (2012) Quantitative XRD analysis of $\{110\}$ twin density in biotic aragonites. Journal of Structural Biology, 180, 458-468.

Tamura, K., Kogure, T., Watanabe, Y., Nagai, C. and Yamada, H. (2014) Uptake of cesium and strontium ions by artificially altered phlogopite. Environmental Science \& Technology, 48, 5808-5815.

Wahlberg, J.S. and Fishman, M.J. (1962) Adsorption of cesium on clay minerals materials. Geological Survey Bulletin, 1140(A), A1-A30.

Zachara, J.M., Smith, S.C., Liu, C., McKinley, J.P., Serne, R.J. and Gassman, P.L. (2002) Sorption of $\mathrm{Cs}^{+}$to micaceous subsurface sediments from the Hanford site, USA. Geochimica et Cosmochimica Acta, 66, 193-211.

Manuscript received December 18, 2014

Manuscript accepted March 10, 2015

Published online May 12, 2015

Manuscript handled by Tsutomu Sato 